\title{
BIZARRE BIO-CITIZENS AND THE FUTURE OF MEDICINE. THE WORKS OF ALEXANDRA DAISY GINSBERG AND AGI HAINES IN THE CONTEXT OF SPECULATIVE DESIGN AND BIOETHICS
}

\begin{abstract}
The article concerns speculative design in the context of bioethics. The author analyzes and interprets projects by designer Alexandra Daisy Ginsberg and Age Haines in relation to modern biotechnologies, future scenarios of medicine and machine ethics.
\end{abstract}

Keywords: speculative design, bioethics, bio art, biotechnology

One of the key features of the Speculative Turn is precisely that the move toward realism is not a move toward the stuffy limitations of common sense, but quite often a turn toward the downright bizarre. ${ }^{1}$

Speculative design, critical design, discursive design, these are just some of the names used to describe designing practices that very strongly resemble art \& science. The three terms used here are not synonymous and will be defined further in the text but they do have certain things in common. The projects are mostly exhibited in art galleries and museums, their main purpose in not commercial, they refer to the future rather than the present and they are strongly embedded in science and technology. When we think about the mainstream design like industrial, fashion, software, interface, graphic or communication designs they share some features, they have to be useful, and that means practical, functional, utilitarian, pragmatic and applicable. Whereas the projects analyzed in this text are the exact opposite of practical, func-

L. Bryant, N. Srnicek, G. Harman (eds.), The Speculative Turn: Continental Materialism and Realism, Re-Press, Melbourne 2011, p. 7. 
tional, utilitarian, pragmatic and applicable and yet they are definitely useful, but in a whole different meaning of the word.

In the book entitled Discursive Design. Critical, Speculative and Alternative Things, designers Bruce and Stephany Tharp make an attempt to draw a cartographic scheme of different kinds of design, depending on the role it plays, the outcomes it gives, and what the designing process looks like. The word attempt is used here because even the authors themselves repeatedly say that the lines they draw are often very blurry, stating that their aim is "not about confining boxes within which designers are expected to operate" ${ }^{2}$ but rather about "making better sense of the activities designers are already engaging in." ${ }^{3}$

According to the Tharps there are certain roles design plays and many different factors that influence designing practices. To answer the question why are certain kinds of design produced the Tharps propose a four-filed framework stating that commercial design is mostly focused on profitability; responsible design is related to social responsibility and puts minorities in the center of its attention; experimental design is a way to explore potential and further possibilities, whereas discursive design provokes reflection - "Just as objects act as prostheses, they can also be deliberately designed as intellectual prostheses." ${ }^{\text {S }}$ So rather than shaping people's activities and routines, discursive design provokes critical reflection, influences the way people think and how they can perceive reality from different perspectives.

According to the Tharps discursive design is a wider category, or rather as they call it genus in relation to taxonomic ranks. The species that fall into the category are adversarial design, anti-design, contestational design, critical design, critical jugaad, design fiction, dissident design, guerrilla futures, interrogative design, radical design, reflective design, speculative design, speculative re-design, tactical media and un-design. ${ }^{5}$ The Tharps define all the subcategories but for the purpose of this text just the two will be elaborated on and that is speculative design, which in line with the authors developed as a critique toward critical design. The former being more focused on imagination, softer in its criticism as the projects are usually set in the future and do not give specific answers or points of view but rather give the viewers space for speculation. The latter being more straight forward and opinionated, intellectual rather than creative and relating to the present.

In his book Critical Design in Context Matt Malpass also characterizes both critical and speculative design defining a method for each category of design but also analyzing the type of satire used, type of ambiguity and object relation. Malpass sees critical design as creating a narrative that situates the object in a certain context, so the narrative is part of the project and is designed in advance. Whereas in speculative

B. Tharp, S. Tharp, Discursive Design: Critical, Speculative and Alternative Things, The MIT Press, Cambridge-London 2018, p. 146.

Ibidem, p. 146.

Ibidem, p. 7.

Ibidem, p. 84. 
design he notices two important features and these are hybridity and technocratic visualization. Hybridity is defined here as situating an object in a certain context other than real, and this way a new narrative is created or some scientific tools can be used to rationalize the object placed in a certain context. ${ }^{6}$

When defining speculative design Malpass also emphasizes the relation to the technoscientific realm and designer's cooperation with researchers and scientists, creating future scenarios as well as "the domestication of up-and-coming ideas in science and applied technology." Critical design, on the other hand, is rather grounded in the present and critically reflects upon what already exists.

Through mechanism of defamiliarization and estrangement, designers extend the critical distance between the object and the user; in so doing, they make striking comment on current sociotechnical, economic, political, cultural, and psychological concerns and find new forms of expression for complex issues. ${ }^{8}$

Anthony Dunne and Fiona Raby, who coined the term critical design, describe what it meant to them in the mid-nineties, how it evolved and what it might mean now. In general their views are a lot less deterministic than the ones stated above and in many ways they are contradictory to what the Tharps and Malpass offer. For Dunne and Raby critical design was more an attitude than a certain methodology and they coined the term in contrast to affirmative design that was more about strengthening the existing situation. Over the years the way thay perceive critical design has changed and now they clearly state that critical design might as well relate to the present as to the future, that it has nothing to do with Frankfurt School or criticism in general. They rather recognize it as a language and thought translated into materiality, and created to engage people. What they also emphasize is how powerful design can be as means for protests and boycotts as well as a tool to raise social awareness. In their reflections about design Dunne and Raby put a spotlight on conceptual design and they differentiate it from the popular definition. Conceptual design is not about a project that has not yet been realized or an early phase of the designing process, it is rather about designing ideas, thus conceptual design in a way relates to conceptual art. Design and art are very closely related, it might not be very true with commercial design, although many might disagree, the similarities are certainly visible when it comes to conceptual design in the sense that Dunne and Raby describe. ${ }^{9}$

What the authors of Speculative Everything... do instead of looking for clear cut definitions of what critical or speculative design is, they show where the inspiration comes from, what is valuable in different projects, how those project are useful for

6 M. Malpass, Critical Design in Context: History, Theory, and Practice, Bloomsbury, London-New York 2019, p. 119.

Ibidem, p. 100.

Ibidem, pp. 107-108.

A. Dunne, F. Raby, Speculative Everything: Design, Fiction, and Social Dreaming, The MIT Press, Cambridge-London 2013, loc. 138-192/1596 (Kindle edition). 
the society and how designers themselves create ideas and ideals rather than projects within certain rules and regulations. Similarly to art history, aesthetics and art theory, some divisibility is useful but then at some point it becomes so absurdly detailed that it is counterproductive.

Hence Speculative Design is a

[...] form of design that thrives on imagination and aims to open up new perspectives on what are sometimes called wicked problems, to create spaces for discussion and debate bout alternative ways of being, and inspire and encourage people's imaginations to flow freely. Design speculations can act as a catalyst for collectively redefining our relationship to reality. ${ }^{10}$

\section{Body enhancement}

\section{CRISPR Emoji, Alexandra Daisy Ginsberg}

In 2017 a British design magazine Disengo asked eleven designers to create an emoji that would be useful in 2018. Each designer was also asked to write a 100 words to explain their choice. One of the designers was Alexandra Daisy Ginsberg who designed a CRISPR emoji. It depicts a pair of scissors, a double helix and a piece of DNA that will be inserted in the helix. To justify her choice Ginsberg wrote a short story as a text message that contained the emoji. It is a message from one partner to the other about a doctor visit concerning having a CRISPR baby instead of a natural one. The procedure seems to be quite costly but probably a good investment as genom editing would help avoid many problems and the baby would be perfect. The text does not only contain the CRISPR emoji but also expressions such as "genetic counseling," "CRISPR baby pack," comparison of CRISPER to IVF and the procedure will be performed as part of a medical trial. ${ }^{11}$

CRISPR Cas9 system is considered one of the biggest biotechnological breakthroughs of the $21^{\text {st }}$ century. It allows specific gene editing through identifying a faulty piece of DNA, cutting it out and repairing it by pasting a new piece.

Over the past 6 years, however, transformative discoveries have shaped the CRISPR (clustered regularly interspaced short palindromic repeats) Cas (CRISPR-associated) toolbox for genetic manipulation on the basis of simpler RNA-guided DNA recognition. This toolbox now provides important scientific opportunities for curing genetic diseases and engineering desirable genetic traits, as well as new approaches to live-cell imaging, high throughout functional genomic screens, and point-of-care diagnostics. ${ }^{12}$

$10 \quad$ Ibidem, loc. 58/1596 (Kindle edition).

11 Official website of the project: https://daisyginsberg.com/work/crispr-emoji (accessed: 11.11.2019).

12 G.J. Knott, J. Doudna, CRISPR-Cas Guides the Future of Genetic Engineering, "Science" 2018, vol. 361 (August), pp. 866-869. 
The technology is very promising, and some of the results prove it works, but it has also sparked major controversies and concerns when Junjiu Huang and colleagues at Sun Yatsen University in Guangzhou in China used it to modify human embryos. The experiment has been considered unethical by many scientists and international organizations up to the point when Science and Nature refused to publish the article by Junjiu Huang and his team. The results were finally published online in Protein \& Cell co-published by Springer and an affiliate of the China's Ministry of Education. ${ }^{13}$

The question with CRISPR emoji is probably not if but rather when we will need it and how will CRISPR technology change our lives. What we are dealing with here is a typical ethical debate related to emerging biotechnologies. In February 2014 National Academies of Science, Engineering and Medicine in the USA published a report entitled Human Genome Editing: Science, Ethics and Governance. The committee of experts gathered and reviewed information, monitored the emerging scientific achievements, and gathered information from scientists, researchers, clinicians, policy maker and the public to produce guidelines and criteria for the use of human genome editing technologies, especially CRISPR Cas9. The main questions concerned how to balance benefits and risks, governing genome editing, clinical applications as well as incorporating societal values. The committee appointed three major settings in which genome editing is applied and these are: "(1) basic research that helps advance understanding of human disease and its treatment; (2) clinical applications to treat or prevent disease or disability in somatic cells (non-reproductive cells), and; (3) clinical applications to treat or prevent disease or disability in germline cells (reproductive cells)." ${ }^{14}$ When it comes to the first laboratory setting the committee concludes that this type of research offers significant opportunities and should continue in accordance to the existing regulatory structure. In case of somatic cell editing for treatment and the conclusions are that the existing regulations should be used but clinical trial should be limited at this time, safety and efficiency should be reevaluated and public input is required before the use is extended. In germline (heritable) genome editing clinical research is permitted but should be limited to compelling purposes of treating and preventing serious disease and disabilities. There is also a set of criteria, with which heritable germline editing is allowed in the USA. The procedures should be under ongoing reassessment and input from the public is vital. When it comes to enhancement the committee decided not to proceed with editing human genome for purposes other than treatment and prevention of diseases and disabilities, they also encourage public discussion and policy debate. ${ }^{15}$

13 J. Kaiser, D. Normile, Embryo Engineering Study Splits the Scientific Community, "Science" 2015, vol. 348 (May), pp. 486-487.

14 National Academies, Human Genome Editing: Science, Ethics, and Governance, Report Highlights, http://nationalacademies.org/cs/groups/genesite/documents/webpage/gene_177260.pdf (accessed: 12.11.2019).

15 Ibidem. 
Even though "designer babies" are still a promise or a threat of the future what is striking in the report is that public debate seems to be considered vital to the policy making process.

\section{Transfigurations, Agi Haines}

The project is a set of realistic sculptures of surgically modified babies. The sculptures are wrapped in white linen the way babies are covered in hospitals right after they are born, and presented in glass containers that look like incubators. So looking at the exhibition is a bit like looking through a glass window that many hospitals used to have in maternity wards so that parents and families can look at the newborns. When you look closely though, the babies are not exactly what they seem as they have body parts that do not exist in healthy newborns. All the alterations in their bodies are the result of surgical procedures. One of them has an extra body opening in the scull behind its ear. Epidermal Myostomy, located in an area with almost no body fat might be useful if the child has to regularly take tablets. Another baby has an organ that looks like a set of gills on its scalp over each ear. Thermal epidermiplasty helps dissipate heat faster, which might be useful with increasing global warming. Another child has a missing toe with an open wound. Podiaectomi might be useful in case of asthma diagnosis. Such soft flashy place will be used for hookworm contraction as these parasites are known for reducing allergic reactions. Bibuccalplasty is an extension of the cheeks that will allow better caffein absorption when working under a lot of stress. The procedure requires special clips that expand the cheeks over a period of three months. ${ }^{16}$

With this project Haines poses some very important questions related to the future of medicine in context of our adjustment to the changing environment. The underlying assumption here is that the issues we are trying to deal with at the moment will remain unsolved or even worsen. Looking at the project from the perspective of Transhumanist theories, as the author herself does, such enhancements can be perceived as our strive for longevity as the more we adjust to the conditions we live in, the higher our life expectancy. Although Ray Kurzweil does not mention the alterations designed by Haines he does describe how different parts of the human body will presumably change in the near future. Since the general path designed by Kurzweil is singularity and since he considers our biological shell as the main obstacle in achieving the goal, what he proposes is to redesign our digestive system, then our blood, followed by heart and other organs and finish with the brain. When it comes to digestion the first changes would be biochemical, that is drugs and supplements, mostly those that reduce the caloric absorption as very low-calorie diet prolonged life. The next step would be nanobots in our bloodstream and digestive tract that would regulate amounts of nutrients. What is interesting is that Kurzweil does not forget that eating

16 Official website of the project: https://www.agihaines.com/transfigurations (accessed: 11.11.2019). 
is also a pleasure so at this point we could eat whatever we wanted and as much as we wanted and the nanobots would control the absorption. Different nanobots would be responsible for dealing with waist so at some point we would not need our liver and kidneys any more. The redesigning of the blood and heart are strongly related as nano robotic blood would circulate on its own the heart would be no longer needed and neither would be lungs, as nanobots would also be responsible for oxygenation. At some point of the transition what is left is the skeleton, skin, sex organs, sensory organs, mouth, upper esophagus and the brain. ${ }^{17}$

Biological evolution did create a species that could think and manipulate its environment. That species is now succeeding and accessing - and improving - its own design and is capable of reconsidering and altering those basic tenets of biology. ${ }^{18}$

But apart from the Transhumanist perspective, Transfigurations can also be interpreted as a dystopian vision of the future, something we should do everything in our power to avoid.

Looking at both CRISPR Emoji and Transfigurations form a different angle it is possible to draw conclusions related to how the fast development of medicine and biotechnologies might force us to making even more difficult decisions related to health and treatment. Both projects concern body enhancement but what if they actually show a future scenario in which the wealthy parents choose genome editing which is costly but pain free and effective, whereas those who cannot afford genetic manipulations decide to perform surgical enhancements, which take some time to recover from but seem effective enough. People are already making similar decisions on daily basis. All those parents who try and gather unbelievable amounts of money to treat their dying children, parents who fight for their lives so that they can bring up their children. According to Nikolas Rose, nowadays we all are biological citizens, and as such we are confronted with new responsibilities. What characterizes biological citizenship is that it is both individualizing and collectivizing. Individualizing in a sense that we take responsibility for our somatic selves in both corporeal and genetic, and collectivizing in the sense of forming collectives that share knowledge and experiences and as such become more powerful than ever before.

This is manifested in a range of struggles over individual identities, forms of collectivization, demands for recognition, access to knowledge, and claims to expertise. It is creating new spaces for public dispute about the minutiae of bodily experiences and their ethical implications. It is generating new objects of contestation, not least dose concerning the respective powers and responsibilities of public bodies, private corporations, health providers and insurers, and indi-

\footnotetext{
17 R. Kurzweil, The Singularity Is Near: When Humans Transcend Biology, Duckworth, London 2013, pp. 299-311.

18 Ibidem, p. 310.
} 
viduals themselves. It is creating level forms for political debate, new questions for democracy, and new styles of activism. ${ }^{19}$

\section{Human-machine interaction}

\section{If you prick us, do we not bleed?, Agi Haines}

If you prick us, do we not bleed? is a realistic, 3D, animatronic human face made out of silicone that is stretched on a wall. The face resembles a death mask or historical, medical imagery - then clay sculptures showing certain diseases or pathologies. The main purpose of the project, according to the author, artist and designer Agi Haines, is to train humans in building relationships with humanoid robots and artificial intelligence. The face, as an "empathy tool," reacts to human emotions depending on their intensity. If the viewers raise their voice at the face it frowns, when they shout it starts crying, and if they scream the robot suffers from a nose bleed. ${ }^{20}$ The title of the project is a quote from William Shakespeare's The Merchant of Venice. Originally Shylock's monologue relates to antisemitism and inhuman treatment of minorities, hence Haines indicates that nowadays we could consider technology not only as an agent (as it is treated in Object Oriented Ontology) but also in context of ethics and moral agency.

In their works concerning machine ethics Michael Anderson and Susane Leigh Anderson use the distinction by James Moor, that is implicit ethical agent and explicit ethical agent. According to Moor an implicit ethical agent is a machine that has been programmed to act ethically whereas an explicit ethical agent is a machine that calculates what would be the best action in ethical dilemma based on available knowledge. Moor also mentions a full ethical agent, who is an adult human being, able to make ethical judgements and can justify them. Although there is no certainty, for now only humans can be full ethical agents as only humans possess consciousness, intentionality and free will. ${ }^{21}$ There are many aspects that have to be taken into account when designing machine ethics. The Andersons begin with the question of whether ethics can be computed and continue with what kind of ethics (teleological or deontological) would be most effective in case of machines. But the issue becomes even more problematic when emotions enter the scene. On the one hand emotions or rather empathy can be very helpful in deciding what would be the right moral action, on the other emotionality is something that often leads humans to making bad deci-

19 N. Rose, The Politics of Life Itself: Biomedicine, Power, and Subjectivity in the Twenty-First Century, Princeton University Press, Princeton-Oxford 2007, pp. 136-137.

20 Official website of the project: https://www.agihaines.com/if-you-prick-us-do-we-not-bleed (accessed: 11.11.2019).

21 J.H. Moor, The Nature, Importance, and Difficulty of Machine Ethics, "IEEE Intelligent Systems" 2006, July-August, pp. 18-21. 
sions as they can get carried away. ${ }^{22}$ The Andersons have implemented two ethical theories, Jeremy was an implementation of Bentham's Hedonistic Act Utilitarianism and W.D of Ross' Prima Facie Duties and in both cases they applied the Principles of Biomedical Ethics. ${ }^{23}$

The implementation of both a single principle ethical theory and a multiple principle theory is an important first step in creating machines that are ethically sensitive. Such systems may serve as ethical advisors as well as tools for the advancement of the theory of Ethics. ${ }^{24}$

\section{BioSpy: A Health-Obsessed Robot for Health Obsessives, Alexandra Daisy Ginsberg}

BioSpy: A Health-Obsessed Robot for Health Obsessives is a short film about a bizarre relationship formed between a human hypochondriac and a surprisingly emotional robot, designed to gather health data. Through building a prototype of a robot that mirrors human behavior Ginsberg asks important questions related to the future of bio design, technological inclusiveness but also erratic technology. We are all very much familiar with the term "human error," which can be perceived in various ways. To begin with "human error" is often evoked as constitutive for human beings, irreplaceable part of the learning process but most of all indispensable part of our strive for perfection. Such error can be a flaw but most often is treated as opportunity. Lately failures have become the center of attention with famous $C V$ of failures by professor Johannes Haushofer, inspired by an article Melany Stefan published in Nature. ${ }^{25}$ Haushofer's last failure proves how important failure has become "2016 - This darn $\mathrm{CV}$ of Failures has received way more attention than my entire body of academic work." 26 The trend includes Caitlin Kirby, a PhD student who wore a skirt made out of rejection letters to her dissertation defense "In the spirit of acknowledging \& normalizing failure in the process." ${ }^{27}$ Not without a reason both Art Electronica and Gdynia Design Days 2018 had the word error in their title, respectively Error - The Art of Imperfection and \#Error.

So far machine errors have never been perceived other than something that should be avoided. But the more human, emotional and erratic technology becomes the more

22 M. Anderson, S.L. Anderson, Machine Ethics: Creating and Ethical Intelligent Agent, "AI Magazine" 2007, vol. 28, no. 4, pp. 15-26.

23 M. Anderson, S.L. Anderson, C. Armen, Towards Machine Ethics, Conference AAAI-04 Workshop on Agent Organizations, Theory and Practice, July 2004.

24 Ibidem.

25 M. Stefan, A CV of Failures, "Nature" 2010, vol. 468 (November), p. 467.

26 J. Haushofer, CV of Failures, https://www.princeton.edu/ joha/Johannes_Haushofer_CV_of_Failures. pdf (accessed: 11.11.2019).

27 C. Ritschel, Independent, https://www.independent.co.uk/life-style/dissertation-phd-doctor-rejection-letter-skirt-caitlin-kirby-a9166866.html (accessed: 11.11.2019). 
we should consider our future relationship. One of the fastest developing fields of research related to technology is Affective Computing, a term coined by Rosalind Picard. It concerns creating computer systems that are able to read, analyze and understand emotions. These often take a form of applications or wearable technology or can even be specially equipped smartphones and perform facial emotions recognition, measure blood pressure and heart beat in relation to our emotional state, interpret body language or analyze our voice. Emotion recognition will be useful for organizations (employee satisfaction, effective workplaces, etc.), retail and marketing (improve user experience and sales), healthcare, smart homes or the devices we use such as computers and smartphones might react to our emotions. To make it more effective these might someday become equipped with Artificial Emotional Intelligence.

Picard had mentioned that

the importance of computers that would have emotion. Emotion is not only necessary for creative behavior in humans, but neurological studies indicate that decision-making without emotion can be just as impaired as decision-making with too much emotion. Based on this evidence, to build computers that make intelligent decisions may require building computers that have emotions. $^{28}$

Both If you prick us, do we not bleed? and BioSpy: A Health-Obsessed Robot for Health Obsessives differ considerably in their material form but pose similar questions referring to machine ethics.

The question that remains unanswered, and is clearly visible in both works, in context of machine ethics is what about ethics towards machines? David J. Gunkel, the author of The Machine Question: Critical Perspectives in AI, Robots and Ethics assumes an interesting perspective when it comes to technological inclusion, comparing our relations with technology to our relations with animals. Beginning with "animal machines" or "animal automata," Gunkel continues with how both animals and machines had not been perceived as moral subjects, how it has changed in the context of animals and how it might change it context of technology. Although his perspective seems far fetched at first, he argues that the anthropocentric attitude to otherness has a long history and on the basis of supremacy, deciding who should be considered a moral subject has been subject to cultural and social pressures. Gunkel mentions what Joanna Żylińska calls "a sliding scale of humanity and personhood" 29 and that historically it has been applied to women, Jews, people of color and many other groups. Later it was, and still is in many cases, used for animals, who were considered machines with reflexes and we extend it very easily to machines being just "tools," completely dependent on humans. When considering ethics towards the Others and Machinic Others in particular, the terms "moral agent" and "moral patient" come up in context of mechanisms of exclusion, mentioned above, but also as

28 R. Picard, Affective Computing, M.I.T Media Lab Perceptual Computing Technical Report, https:// affect.media.mit.edu/pdfs/95.picard.pdf (accessed: 11.11.2019).

29 J. Żylińska, Bioethics in the Age of New Media, The MIT Press, Cambridge-London 2009, p. 12. 
mechanisms of inclusion. Referring to animal rights theorists such as Peter Singer and Tom Regan, Gunkel considers the historically complicated term person as if it is defined in a certain way, it would, based on traditional philosophical concepts, open the possibility of being a moral agent to machines. But then again How do we prove that they are conscious beings or whether they possess reason and rationality?

In the end Gunkel admits that his reflections upon machines and moral agency were in fact a failure but not because it is impossible to decide, but mostly because the concept of moral agency evolved for so long that at the moment it is unclear what it actually means to be a moral agent. ${ }^{30}$

Although this could be called a failure, it is particularly instructive failing, like any failed experiment in the empirical sciences. What is learned from this failure - assuming we continue to use this obviously negative word - is that moral agencies not necessarily something that is to be discovered in others prior to and in advance to their moral consideration. Instead, it is something that comes to be conferred and assigned to others in the process of our interaction and relationships with them. ${ }^{31}$

\section{Controversies}

Nuffield Council on Bioethics is an independent organization that examines and reports on ethical issues related to biology and medicine. They do research, publish reports, get involved in policy making and perform independent examinations. ${ }^{32}$ In their report entitled Emerging Biotechnologies: Technology, Choice and the Public Good $^{33}$ they characterize emerging biotechnologies, in contrast to established biotechnologies, as "particularly sensitive to contextual factors," which can influence how they evolve and shape but also what is crucial that "they utilize or effect living things, and therefore engage the public interest in distinctive ways." Chapter 2 of the report entitled Biotechnology promises and expectations ${ }^{34}$ characterizes different kind of emerging biotechnologies and continues with a subtitle Biotechnologies Visions. What the authors call a Discursive context surrounding biotechnologies consists of different attitudes and perspectives of perceiving the developments. Even though professional scientists are usually very cautious when it comes to possible outcomes of their research, the influence of other stakeholders such as politicians, entrepreneurs, the public, media and other institutions may sometimes distort the actual

30 D. Gunkel, The Machine Question: Critical Perspectives in AI, Robots and Ethics, The MIT Press, Cambridge-London 2012, pp. 24-85.

31 Ibidem, p. 91.

32 Official website of Nuffield Council on Bioethics: http://nuffieldbioethics.org (accessed: 11.11.2019).

33 Report Emerging Biotechnologies: Technology, Choice and the Public Good, http://nuffieldbioethics. org/project/emerging-biotechnologies (accessed: 12.11.2019).

34 Ibidem. Chapter two: Biotechnology Promises and Expectations, http://nuffieldbioethics.org/wp-content/uploads/2014/07/Emerging_biotechnologies_Chapter2.pdf (accessed: 12.11.2019). 
vision of the research. Emerging biotechnologies give hope and are generally rather "promissory by nature" but the likelihood of their future existence or use depends not only on rationality but also how these expectations are influenced by language, values and experience that form very influential "folk narratives." According to the authors creating a vision of the future including the "knowledge, practice, products and application" of a certain biotechnology has two effects. It "foreshortens" how we perceive a time scale and it "tunnels" both technology and social policy. So the public as well as all investors imagine that their expectations will be fulfilled faster and their perception is limited to certain aspects of the emerging biotechnology.

While folk narratives and descriptive models may reflect past experience, when they are projected into the future as a way of organizing expectations, they may obscure ambiguities and uncertainties that may be significant for decision making and policy. ${ }^{35}$

The report continues with Imported technological visions, which may be developed by a vision of the world that certain biotechnology might bring. These utopias and dystopias are called technoscientific imagery or sociotechnical imagery and are formed mostly by assumptions that the authors refer to as "framing." These assumptions come from realms other than technology, often from culture and can be closely related to social and political objectives or globalization. The problem occurs when these assumptions influence decision-making processes as they are often very individual and the future vision might not be desirable for the person or a group. The authors later describe grander narratives that relate to technology that contain metaphors that are referred to as "conscious adaptations of language" and might be also called biology's pop culture. To finish with a term "cultivation," that refers to the exposure of the public to science fiction, films and video games and science journalism that shapes the expectations of the public but also influence the world of science.

A task of this Report is therefore to define modes of decision making that avoid the foreshortening and tunneling that comes of misrepresenting the complexity of the development and innovation context and the possibility of alternative pathways. To do so is to open up new opportunities for ethical reflection that lie out with dominant narratives linking prospective biotechnologies and social objectives. So far, we have been largely concerned with descriptive questions about the nature and process of emergence and how it is represented. ${ }^{36}$

Among literature that the authors of the report refer to, there is an article entitled Compressed Foresight and Narrative Bias: Pitfalls in Assessing High Technology Futures by Robin Williams. ${ }^{37}$ Williams describes compressed foresight as simplification of technology often in a manner of utopian or dystopian visions but also presenting possible futures as if they were already here. According to Williams this

\footnotetext{
35 Ibidem, p. 35.

$36 \quad$ Ibidem, p. 38.

37 R.A. Williams, Compressed Foresight and Narrative Bias: Pitfalls in Assessing High Technology Futures, "Science and Culture" 2006, no. 15(4), pp. 265-289.
} 
mechanism leads to misinterpretations, high and unrealistic expectations and is very deterministic. One of the paradoxes of the present mentioned by Williams is that on the one hand everyone is expecting results from technological and scientific research as these improve economies, bring better quality of life, on the other, social concerns related to ethics, environment and health within the field of science and technology, seem to "impede acceptance of a technology and result in a failure of innovations. Advance in science is both imperative and vulnerable!" For Williams scientists and engineers have been forced to take those social concerns into consideration, for the first time in history they cannot focus only on the technicalities of their research since funding is offered only to those who address the issues. Not only do scientists and engineers have to cooperate with ethicists, and social scientists, but also "diverse lay publics who are seen as to possess the concepts and methodologies and legitimacy to help them address it." 38

The four speculative design projects described in this text are examples of the role this type of artistic practice can play in modern society. Unlike the authors of Nuffield Council on Bioethics report or Robin Williams, I strongly believe that the complexity and depth of the designs bring about powerful tools for making science and technology more meaningful. They allow as to grasp not only the technology or biotechnology itself, but also their epistemological and ethical dimensions. This way scientific advances become less distant and abstract, and more part of our everyday lives. We get the opportunity to build certain relationships with science and technology, but ones that are based on reflection, knowledge, responsibility and awareness rather than just apologia, fear or promises. In a way we get to experience the world that is yet to come, and thus become ready for it, adjust to what we accept and prevent what seems inadmissible.

My argument is that speculative and critical design may be very effective means of science contextualization and thus the process of shaping and fostering the relationship of science and society. But what is important I do not mean a simple intermediary, that translates science and technology into a different language, but rather as part of a larger shift or even co-evolutionary processes that Helga Nowotny, Peter Scott and Michael Gibbons call mode- 2 society and mode- 2 science. ${ }^{39}$ According to Nowotny, Scott and Gibbons the process consists of four intertwined shifts where the first one relates to a more open system of knowledge production, the second to the process of reverse communication, the third to the process of contextualization, and the fourth to the range of perspectives found in the agora. Re-thinking Science... authors associate the changes in knowledge production with science and society becoming more transgressive and blurring boundaries in between them due to economic, political and societal changes. The reverse communication relates to the society that

38 Ibidem.

39 H. Nowotny, P. Scott, M. Gibbons, Re-thinking Science: Knowledge and the Public in the Age of Uncertainty, Polity Press, Cambridge 2001, p. 245. 
finally has a chance and means to "talk back" to science due to certain shifts in power distribution. Contextualization is based mostly on re-negotiating and re-interpreting science validity that can no longer be "disciplinebound" but should become "socially robust" and "sensitive to much wider range of social implications." as "the space in which societal and scientific problems are framed and defined, and where what will be accepted as a 'solution' is being negotiated." 41

Critical and speculative design are very distinctly situated within all those processes that Nowotny, Scott and Gibbons describe. Not only are those projects answers for the demands of more educated and ethically aware society, but also they are created in cooperation with scientists and engineers so that they also represent the changes in science. They may be perceived as the "talking back" to science that has been in monologue for centuries, and as for the questions posed by designers in their practices, they most definitely widen the perspective of science validation by adding new contexts. Last but not least the galleries, science museums, science centers and all other places where critical and speculative designs are exhibited, become a new kind of agora. These institutions create tailor made environment to discuss scientific and societal issues. Design exhibitions are typically curated into events with experts (not only scientists), panel discussions, workshops, hackathons, maker spaces, open laboratories, science shops and many other educational formats that help mode-2 and mode-2 science engage in mutual ventures. Such processes "lead to the social distribution of knowledge, knowledge that is valid not only inside but also outside the walls of laboratories." ${ }^{42}$

\section{Bibliography}

Anderson M., Anderson S.L., Machine Ethics: Creating and Ethical Intelligent Agent, "AI Magazine" 2007, vol. 28, no. 4, pp. 15-26.

Anderson M., Anderson S.L., Armen C., Towards Machine Ethics, Conference AAAI-04 Workshop on Agent Organizations, Theory and Practice, July 2004.

Bryant L., Srnicek N., Harman G. (eds.), The Speculative Turn: Continental Materialism and Realism, Re-Press, Melbourne 2011.

Dunne A., Raby F., Speculative Everything: Design, Fiction, and Social Dreaming, The MIT Press, Cambridge-London 2013.

Gunkel D., The Machine Question: Critical Perspectives in AI, Robots and Ethics, The MIT Press, Cambridge-London 2012.

Haushofer J., CV of Failures, https://www.princeton.edu/ joha/Johannes_Haushofer_CV_of_ Failures.pdf (accessed: 11.11.2019).

Kaiser J., Normile D., Embryo Engineering Study Splits the Scientific Community, "Science" 2015, vol. 348 (May), pp. 486-487.

\footnotetext{
$40 \quad$ Ibidem, p. 246.

${ }^{41} \quad$ Ibidem, p. 247.

42 Ibidem, p. 248.
} 
Knott G., Doudna J., CRISPR-Cas Guides the Future of Genetic Engineering, "Science” 2018, vol. 361 (August), pp. 866-869.

Kurzweil R., The Singularity Is Near: When Humans Transcend Biology, Duckworth, London 2013.

Malpass M., Critical Design in Context: History, Theory, and Practice, Bloomsbury, LondonNew York 2019.

Moor J.H. The Nature, Importance, and Difficulty of Machine Ethics, "IEEE Intelligent Systems" 2006, July-August, pp. 18-21.

Picard R., Affective Computing, M.I.T Media Lab Perceptual Computing Technical Report, https://affect.media.mit.edu/pdfs/95.picard.pdf (accessed: 11.11.2019).

Report Emerging Biotechnologies: Technology, Choice and the Public Good, http://nuffieldbioethics.org/project/emerging-biotechnologies (accessed: 12.11.2019).

National Academies, Human Genome Editing: Science, Ethics, and Governance, Report Highlights, http://nationalacademies.org/cs/groups/genesite/documents/webpage/gene_177260. pdf (accessed: 12.11.2019).

Nowotny H., Scott P., Gibbons M., Re-thinking Science: Knowledge and the Public in the Age of Uncertainty, Polity Press, Cambridge 2001.

Ritschel Ch., Independent, https://www.independent.co.uk/life-style/dissertation-phd-doctor-rejection-letter-skirt-caitlin-kirby-a9166866.html (accessed: 11.11.2019).

Rose N., The Politics of Life Itself: Biomedicine, Power, and Subjectivity in the Twenty-First Century, Princeton University Press, Princeton-Oxford 2007.

Stefan M., A CV of Failures, "Nature" 2010, vol. 468 (November), p. 467.

Tharp B., Tharp S., Discursive Design: Critical, Speculative and Alternative Things, The MIT Press, Cambridge-London 2018.

Williams R., Compressed Foresight and Narrative Bias: Pitfalls in Assessing High Technology Futures, "Science and Culture" 2006, no. 15(4), pp. 265-289.

Żylińska J., Bioethics in the Age of New Media, The MIT Press, Cambridge-London 2009. 